Association for Information Systems

AIS Electronic Library (AISeL)

Wirtschaftsinformatik 2021 Proceedings

Track 4: Creating value through digital

innovation in health care

\title{
Patients' Attitudes toward Apps for Management of a Chronic Disease
}

Paul Alpar

Philipps-Universität Marburg

Thomas Driebe

Philipps-Universität Marburg

Follow this and additional works at: https://aisel.aisnet.org/wi2021

Alpar, Paul and Driebe, Thomas, "Patients' Attitudes toward Apps for Management of a Chronic Disease" (2021). Wirtschaftsinformatik 2021 Proceedings. 8.

https://aisel.aisnet.org/wi2021/WCreating/Track04/8

This material is brought to you by the Wirtschaftsinformatik at AIS Electronic Library (AISeL). It has been accepted for inclusion in Wirtschaftsinformatik 2021 Proceedings by an authorized administrator of AIS Electronic Library (AISeL). For more information, please contact elibrary@aisnet.org. 


\title{
Patients' Attitudes toward Apps for Management of a Chronic Disease
}

\author{
Paul Alpar ${ }^{1}$, Thomas Driebe ${ }^{2}$ \\ ${ }^{1}$ Philipps-University of Marburg, Department of Mathematics and Computer Science, Marburg, Germany \\ alpar@staff.uni-marburg.de \\ ${ }^{2}$ Philipps-University of Marburg, School of Business and Economics, Marburg, Germany \\ driebe@staff.uni-marburg.de
}

\begin{abstract}
We model the intention of patients to use a telehealth app for the management of a chronic disease. Our model integrates the health belief model with a model of information technology acceptance to reflect the technology- and health-related parts of the intention. The intention of non-using patients to use the app is influenced by their hedonic motivation and social influence. An analysis of sub-groups reveals deeper insights: Patients without access to the app would use it based on the expected performance and their self-efficacy. Patients who do not use the app despite having access to it would use it if influenced by their social environment and if they perceive their disease to be severe. A third group does not even know whether they can use the app. The results show that proper education of patients and people influencing them is necessary even in the case of chronic diseases.
\end{abstract}

Keywords: Chronic Disease Management, M-Health, Telehealth, Technology Adoption, Patient Behavior

\section{Introduction}

Treatment of chronic diseases has been continuously improved over the last decades, with an increasing focus on patient self-care [1]. Chronic diseases differ from acute diseases (that last only a short time) in their impact on patients as well as on the healthcare system and are the most common cause of death worldwide [2]. M-health is well suited to support chronic disease patients [3] and it is expected to improve their treatment adherence [2]. It has also been shown analytically that m-health can be superior to the office-visit model with respect to patient's average life expectancy and expected total lifetime utility [4]. The benefits come mostly from additional opportunities for intervention by the health care provider. We concentrate on hemophilia, as an exemplary chronic disease. It is often "neglected" by research on mhealth [5] because the number of patients is comparably low at 400,000 hemophiliacs [6] vs. 400,000,000 diabetics [7] worldwide. The hemophilia treatment is named replacement therapy because it replaces the blood clotting factors missing in

16th International Conference on Wirtschaftsinformatik,

March 2021, Essen, Germany 
hemophiliacs. Clotting factors help to close wounds and stop internal bleedings. The required substance for hemophilia treatment, a synthetic blood clotting factor, is costly and prone to overconsumption, since the precisely needed dose is difficult to determine, but overdosing has no negative health consequences [8]. In a study regarding the outpatient expenditures for 34,000 children with chronic diseases in California, only 145 children from this group had hemophilia but they accounted for $41 \%$ (195\$ million) of the state spending for this group [9]. M-health supported documentation offers advantages to patients and the health care system, as they provide data about the success of different therapy approaches and allow for a more precise dosage and thus less overconsumption. This study uses combined models from health psychology and information systems to analyze which conditions facilitate the application of $\mathrm{m}$-health for support of chronic diseases, esp. hemophilia.

\section{$2 \quad$ Background}

\subsection{Hemophilia}

Hemophiliacs are prone to longer bleedings after injuries and possible internal bleedings, e. g., inside joints or the brain. This may result in disabling arthropathy and, in severe cases, death [8]. Regular treatment (replacement therapies) produces better results concerning the prevention of arthropathy (compared to on-demand), but patients may not comply with the therapy and health care providers are hesitant to finance it [8]. This study researches hemophiliacs in Germany.

Chronic disease management (CDM) apps, here specifically for hemophilia treatment, are an example of m-health support. Since September 2020, hemophiliacs in Germany receive their prescription from hematologists and their factor supply in pharmacies. Hematologists are organized in hemophilia treatment centers (HTC), which range from big comprehensive care centers with approx. 40 patients and with specialized personal to individual physicians with some hemostaseological experience. They are required by the German blood transfusion law to report their patients' factor usage to the German Hemophilia Registry (DHR). For this purpose, HTCs depend on an accurate documentation by the patients or their legal guardian. Patients also report relevant occurrences like joint bleedings.

Now, most patients document their factor usage in a paper notebook, which the nurses in the HTC use to update the patient data on each visit. This paper-based documentation is prone to several errors. Adherence to documentation and treatment is difficult to verify, since the only time patients must show their records is when visiting their physician, which can be just once a year. Patients often make updates just before the visit, which can result in wrong dates, for example. The notebooks do not provide a standardized way of recording joint bleedings. Therefore, patients improvise and often do not enter information that is precise enough.

Alternatively, two apps have been separately developed to facilitate the documentation via easier input (scan of the factor charge number) and digital data transfer to the centers. These apps offer additional features and advantages. For 
example, physicians can utilize them to monitor patients' adherence to regular prophylactic therapy. Disabling arthropathy as the most common consequence of hemophilia is also easier prevented by CDM apps, since they allow to precisely record the bleedings: the patient simply taps the location of the bleeding on a body drawing, which provides the physician with an overview of all occurrences. In addition, the data can be immediately forwarded to a hematologist. The collected data can also help to better monitor the cost effectiveness of different treatment regimens [10]. HTCs need to have the corresponding infrastructure, and therefore, support only one of the apps or none at all. Both apps are certified medical products.

To summarize, hemophilia is different from chronic diseases like diabetes, because on one hand an exact tracing of the medication taken is needed (in the past blood transfusions were sometimes contaminated with diseases of the blood donors). On the other hand, overdosage "only" burdens insurances and society but not patients.

\subsection{Research Problem}

There is no law in Germany that mandates the use of an app. Even if an HTC supports an app, it is not allowed to demand its use from a patient or to put a non-user into any disadvantage compared to patients who use the app. Also, no physician can deny treatment if a patient does not want to use the app. Each patient can decide absolutely freely whether to use the app. Models of technology acceptance are well-suited to describe this voluntary use of an app. One of the most advanced and comprehensive of such models is UTAUT2 (Unified Theory of Acceptance and Use of Technology 2). It is based on several previous behavior models like the technology acceptance model (TAM), TAM2, and the theory of reasoned action (TRA) [11]. Its constructs cover IT aspects as well as some psychological aspects. However, it does not contain healthrelated constructs which can be very important in the context of chronic diseases.

Psychology of medicine has developed models that take health believes into account, specifically related to an illness or behavior which can lead to an illness. These models can be used to measure intentions of people to change their behavior or to measure the effectiveness of activities that try to make people adhere to medical advice. The measures need not demand any use of technology by patients. For example, warnings about consequences of smoking on cigarette packages do not expect any technology use. For such purposes models like the health belief model (HBM) have been developed [12]. The HBM was originally developed to explain and predict the acceptance of medical recommendations [13]. It assumes that, health-related actions depend on an individual's perception of his own health status and assessment of these actions. This perception is formed by how threatened individuals feel and how beneficial the possible action may be. The threat is determined by the perceived seriousness and susceptibility of the disease, and the decision is further weighted against costs and benefits of the action. Additionally, the decision is influenced by cues to action, represented by health events or physician advice [13].

Our research goal is to systematically develop an adoption model for the use of an app in the context of a chronic disease. The app helps to manage a life-threatening disease. The resulting model can be applied to gain knowledge in this specific context. 
Modeling the use of treatment-supporting apps for (chronic) diseases, requires consideration of IT and health-related issues [14].

In some cases, older acceptance models are used despite the existence of newer models with better conceptual coverage. Leanness of the combined model was often achieved by simply omitting some constructs. This is problematic because important concepts may be missing, and explanations of the problem can be biased. TAM and HBM show conceptual similarity between their constructs (e. g., perceived usefulness) [15]. We create a combined model systematically by combining constructs which are conceptually similar but retain the conceptual coverage of HBM and newer acceptance models. This way, we achieve an adequate conceptual coverage and a relatively lean model.

\section{$3 \quad$ Model Building}

We start with health-related constructs provided by the HBM, then continue with shared constructs and discuss the technology-related constructs from UTAUT2 at the end.

The HBM-exclusive part of the model contains the health-specific constructs perceived susceptibility and perceived seriousness. They may be viewed as an individual's threat appraisal, which is part of several HBMs [12]. It is an essential part of health behavior, since every coping behavior (e. g., using an m-health app) needs to be induced by a perceived threat [16]. The versions of HBM are not consistent in the operationalization of the links between susceptibility, seriousness, threat, and behavior [17]. Following previous studies, we measure susceptibility and seriousness as separate dimensions to achieve a more differentiated prediction [16]. High values of susceptibility and seriousness, positively influenced the behavioral intention in other cases [18]. The construct of perceived threat originates in psychological research about fear, where the influence of fear on behavior change is described in various contexts, including health [16]. The perceived seriousness is viewed as the most common variable [16] and has consistently been found to facilitate behavior change [19]. Accordingly, we hypothesize that a hemophiliac perceiving his illness as more severe will more likely use the digital documentation:

H1: Perceived seriousness has a positive effect on usage intention.

Perceived susceptibility constitutes the second component of fear [16, 20]. E. g., it is used in the research of preventive breast cancer mammography [20]. The construct has consistently shown to facilitate behavior change, the more a subject was aware of and felt susceptible to a disease [12]. It does not make sense to consider the fear of getting hemophilia, because it is hereditary. In our study, threat is specified as the threat of disabling arthropathy caused by joint bleeding since this is a common and dangerous consequence of hemophilia. If a patient perceives himself as more susceptible to suffer from joint bleeding, he is more likely to switch to m-health documentation in order to better monitor and prevent the bleedings Therefore, we propose:

H2: Perceived susceptibility has a positive effect on usage intention.

Self-efficacy describes the degree of a person's ability to perform an intended behavior [21]. It is an effective predictor of behavioral intention and has been later 
added to the HBM [12], while it was included in the Protection Motivation Theory (PMT), an alternative to HBM, from the beginning [16]. Users confident in their ability to effectively use technology will be more likely to use that technology. This positive influence has been validated in general models of technology acceptance [22] as well as in studies focusing on m-health [12]. It has also been found to be the most decisive predictor in studies researching long-term health behavior, e. g., dietary behavior [23]. Here, self-efficacy describes a patient's ability to intuitively use smartphone apps. It is assumed that a patient, who perceives himself as efficient in the use of apps and smartphones in general, is more likely to also use the smartphone-based documentation.

H3: Self-efficacy has a positive effect on usage intention.

Next, we discuss constructs that are found both in HBM and UTAUT2. The integration of these models allows for a reduction of latent constructs where they conceptually overlap. The similarity of the constructs can be derived from their definition and operationalization. The HBM constructs are viewed as easy to adapt for specific use [17] and they have been shown to be valuable predictors using alternative operationalizations [13].

Performance expectancy is defined as the degree to which an individual believes that using a system will help him to increase performance [22]. It proved to be a strong predictor of behavioral intention in studies with a healthcare context [24]. Perceived benefits in the HBM were defined as the likelihood of an action to be taken depending on an individual's perception of the effectiveness of the action [13]. Therefore, both are perceptions about effectiveness, differentiating only between an action and (IT) system. In our study, the action is defined as using a system (the app), therefore the constructs are similar. This notion of benefit has been used by various researchers to predict health behavior $[13,18]$. Here, benefits provided by the app are, for example, improved bleeding monitoring and facilitated exchange with hematologists. An extensive literature review in the domain of telehealth treatment of chronic diseases identified perceptions of effectiveness as a possible facilitator to tele-homecare programs [25]. We assume, therefore, that an increase in the perceived benefits of an app-based documentation will increase a patient's intention to use it.

H4: Performance expectancy has a positive effect on usage intention.

Effort expectancy describes the ease of using a technology [11]. Perceived barriers are defined as potential impeding aspects of a health action [13]. These can be described as "difficulty of use" which is the opposite of ease of use. However, both descriptions are guided by the same idea and can be operationalized in the same way. Documentation apps face two types of barriers: the software must match the technical abilities of users and their health knowledge. Technical barriers can be slow loading and responses while a medical barrier may be the use of terms the patient is not familiar with. The apps need to present easy interactions that give medically and technically clear instructions. We assume that if the user expects such problems, his intention to use the app will decline.

H5: Effort expectancy has a negative effect on usage intention.

Social Influence (e. g., advice from family, friends, or physicians) has been found to be another strong predictor of behavior intention [11]. In a recent study on patient adoption decisions of a diabetes management app, it had the strongest positive influence [26]. Concerning social influence, it is described as the degree to which an individual 
perceives that important others believe he or she should use a new system [22], while the cues to action encompass influence exerted by significant others [17]. Thus, the constructs may be considered to be similar. Social influence is also found in general behavioral theories like TRA and TPB, where subjective norm is included as perceived social pressure to perform a certain behavior [27]. Advice is usually a positive, awareness-raising factor and will, therefore, exert a positive influence [12]. In previous studies, social influence has sometimes not been an important factor for determining behavior regarding health technology [28], but those studies mainly applied UTAUT to health care professionals. As this study focuses on patients, who normally heed their physician's advice, social influence is expected to take a more significant role. Another study showed physicians to be viewed as reliable sources concerning health app suggestions [29]. In sum, this study assumes advice from physicians and/or friends to increase the intention of patients to use smartphone documentation, since they want to satisfy their social group's expectations.

H6: Social influence has a positive effect on usage intention.

The technology-exclusive part of our model consists of the UTAUT2 constructs facilitating conditions and hedonic motivation. Facilitating conditions describe the availability of physical resources aiding in the use of m-health (e. g., smartphone) as well as support by friends or an introduction course given by the care center [11]. They have been found to reliably predict behavior intention in a health-care context [12]. Here, facilitating resources specifically include an easy to use smartphone and the possibility to ask for help when using the app. We assume that better resources and support will increase the likelihood of using an app-based documentation.

H7: Facilitating conditions have a positive effect on usage intention.

Hedonic motivation describes the fun or pleasure derived from using a technology [11], m-health in this case. It represents an intrinsic motivation within UTAUT [11]. Although our study is conducted in the context of CDM, hedonic motivation may be present because apps represent a much newer technology than paper-based documentation. Patients may find satisfaction in using new technology for managing their disease. Therefore, a patient experiencing more pleasure in using apps is expected to be more likely to use an app-based documentation:

H8: Hedonic motivation has a positive effect on usage intention.

UTAUT2 further proposes price value and habit as constructs. Price value is excluded, since the sample only used m-health apps distributed by the HTCs free of charge. Habit was dropped from the model, since there is no possibility for patients to use a similar app before adoption and develop correlated habits. While fitness or health tracking apps also serve tracking purposes, their use is not in a life-threatening context. The consequences of not using them for days are usually not severe. All moderators proposed by UTAUT2 were included except gender, because hemophilia only affects males.

Figure 1 presents the complete research model while making the origins of concepts explicit. It also shows where previous models are overlapping and can be made leaner in our case. 


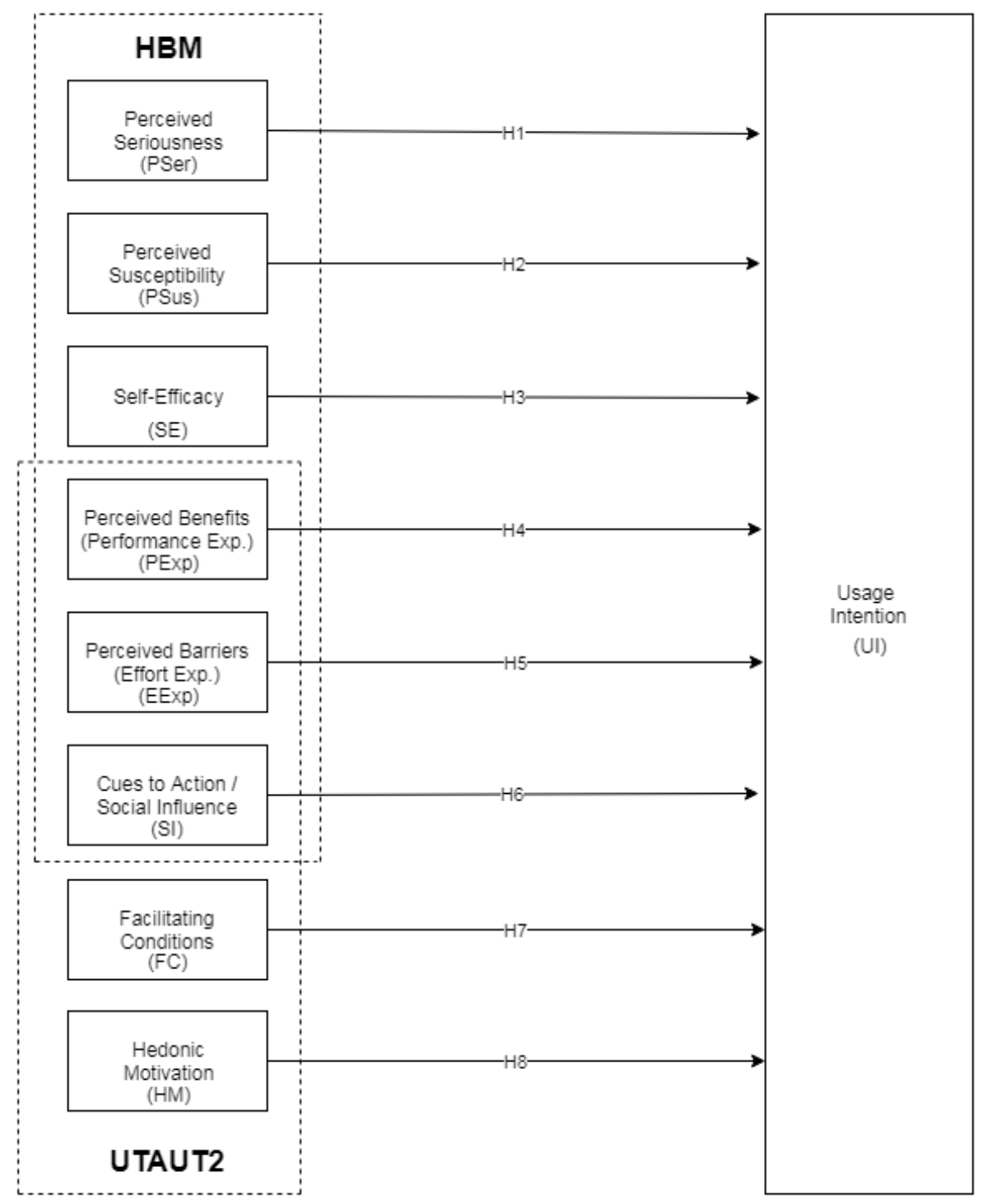

Figure 1: Research model with UTAUT2/HBM overlap

\section{Sample \& Data Collection}

To test the proposed model and hypotheses, a survey was conducted with support of the two major German hemophilia associations of patients. They have more than 3250 members in sum $[30,31]$ which includes patients, their relatives, and physicians. The unique number of patients is not exactly known; we estimate it, based on talks with experts, at about 3000. The associations aided in distributing the survey to their 
members via mail, e-mail, or as a link on their home page but no follow-up was possible because respondents were absolutely anonymous. The e-mail contained a link to the online version of the survey, while the mail contained a printed version with a return envelope. We received 144 responses in total. This amounts to less than $5 \%$ of the population of unique patients in both associations. There are three possible reasons for the relatively low return. First, most current users of the app did not care to participate since they are aware of $\mathrm{m}$-health in this case. Second, patients with the mild or moderate form of hemophilia rarely use hemophilia medication and barely document anything. Third, due to the rare occurrence of hemophilia relative to other chronic diseases, the patients are frequently asked to participate in surveys for medical research. The survey was designed to differentiate between users and non-users and contained accordingly different questionnaire sections for them. From the total, 71 respondents were using an app. These patients perceive to have a significantly better knowledge about hemophilia than non-users. In this research, we were interested in the 73 respondents who do not use any app to document their illness, yet. Eleven responses were excluded because of suspicious answer patterns (always the same answer) and contradictory answers to reverse questions, leaving $\mathrm{n}=62$.

\section{$5 \quad$ Measures \& Instruments}

In addition to the questions related to the above research model, several socio-cultural and health-specific items were asked. The additional questions include whether the survey was answered by the hemophiliac himself or his legal guardian, the age, and the way they document their disease now (app or paper). Furthermore, information on an individual's knowledge about hemophilia was collected since it was determined as a possible variable in health behavior [32]. The participants were also asked to state their objectively measured severity of hemophilia. Table 1 provides insight into the sample.

Table 1: Sample statistics

\begin{tabular}{|c|c|c|}
\hline Variable & Mean (SD) / distribution & Measurement \\
\hline Age & $39.6(19.84)$ & \\
\hline $\begin{array}{l}\text { Knowledge by } \\
\text { severity }\end{array}$ & $\begin{array}{l}\text { Mild: } 2.33(0.71) \\
\text { Moderate: } 2.71(0.76) \\
\text { Severe: } 2.94(0.73)\end{array}$ & $\begin{array}{l}\text { Not existing (1) - } \\
\text { Perfect (5) }\end{array}$ \\
\hline $\begin{array}{l}\text { Degree of } \\
\text { hemophilia }\end{array}$ & & $\begin{array}{l}\text { Mild (1), moderate } \\
\text { (2) and severe (3) }\end{array}$ \\
\hline Health status & $73.45(24.13)$ & $\begin{array}{l}\text { Bad (0) - Perfect } \\
(100)\end{array}$ \\
\hline
\end{tabular}


The (perceived) knowledge about hemophilia rises with the severity of the disease. When adding non-users (62) and users (71), the percentage of severe cases in our survey is $80 \%$. This is higher than in the general population where the share of severe cases of all hemophilia cases is estimated to be at $60 \%$. First, the number of severe cases among association members is probably bigger than in the general population because these patients are more concerned with their disease and its treatment than patients with mild or moderate hemophilia. Second, the interest of patients with severe hemophilia in new CDM approaches is probably bigger than of other patients so they are more likely to answer a related questionnaire.

Most model constructs were tested using scales derived from previous research. We used the HBM's main constructs perceived susceptibility, seriousness, benefits, and barriers [33]. The measurement of perceived barriers and benefits is also used to represent effort and performance expectancy, these constructs overlap with UTAUT2. We follow previous studies in the e-health domain [34] and view self-efficacy as the ability to use e-health applications. The scale was taken from a previous study [35] and altered to specifically apply to CDM apps. The scales for measuring the factors facilitating conditions and hedonic motivation are based on a previous UTAUT2 study [11]. The scale for the integrated social influence/cues to action construct is adopted from a study that also combines UTAUT and HBM [36].

It was necessary to decrease observation dropout due to missing values given the small size of the sample. Therefore, Markov-Chain-Monte-Carlo imputation was used to provide viable substitutes for missing values. The missing values were tested to be missing at random. Ten values from eight respondents were imputed. Table 2 sums up the used constructs and Cronbach's $\alpha$ within the present study. The recommended threshold for Cronbach's $\alpha$ is 0.7 , with values lower than that acceptable in exploratory studies [37]. Only Social Influence does not provide a satisfying $\alpha$ but it is considered close with a value of $\alpha=0.69$. Facilitating Conditions and Self-Efficacy score the highest means (Table 2), suggesting that the confidence and support to use digital documentation is present.

Table 2: Variables

\begin{tabular}{llll}
\hline Variable & Abbreviation & Cronbach's $\boldsymbol{\alpha}$ & Mean (SD) \\
\hline $\begin{array}{l}\text { Usage intention } \\
\begin{array}{l}\text { Perceived } \\
\text { Susceptibility }\end{array}\end{array}$ & UI & 0.96 & $3.67(1.66)$ \\
$\begin{array}{l}\text { Perceived Seriousness } \\
\text { Performance }\end{array}$ & PSer & 0.95 & $3.51(1.64)$ \\
$\begin{array}{l}\text { Expectancy } \\
\text { Effort Expectancy }\end{array}$ & PExp & 0.88 & $3.05(1.23)$ \\
$\begin{array}{l}\text { Social Influence } \\
\text { Facilitating }\end{array}$ & EExp & 0.88 & $2.76(1.14)$ \\
$\begin{array}{l}\text { Conditions } \\
\text { Hedonic Motivation }\end{array}$ & FC & 0.88 & $2.05(0.88)$ \\
Self-Efficacy & HM & 0.69 & $2.47(1.10)$ \\
\hline
\end{tabular}




\section{$6 \quad$ Analyses}

Further analyses are conducted with PLS-SEM in SmartPLS3 and with Stata 14.1. First, a correlation analysis is conducted to detect possible antecedents to behavioral intention. While not providing predictive ability, the correlation analysis allows to determine possible relationships. Second, a PLS-SEM is calculated to test the research model. Third, several multiple regression analyses are carried out to extract more information concerning relevant subgroups of the sample because their size is too small for a PLS analysis. The correlation matrix between the variables given in the previous chapter and behavioral intention is presented in Table 3 .

Table 3: Correlation Matrix

\begin{tabular}{|l|l|l|l|l|l|l|l|l|l|}
\hline & UI & PSus & PSer & PExp & EExp & SI & FC & HM & SE \\
\hline UI & 1 & & & & & & & & \\
PSus & 0.16 & 1 & & & & & & & \\
PSer & $0.26 *$ & $0.50 * * *$ & 1 & & & & & & \\
PExp & $0.47 * * *$ & -0.09 & 0.00 & 1 & & & & & \\
EExp & $-0.29 * *$ & -0.21 & -0.21 & 0.02 & 1 & & & & \\
SI & $0.39 * * *$ & 0.08 & 0.10 & $0.29 *$ & -0.01 & 1 & & & \\
FC & 0.06 & 0.07 & 0.07 & 0.04 & $-0.32 * *$ & $0.22 *$ & 1 & & \\
HM & $0.67 * * *$ & -0.07 & 0.14 & $0.60 * * *$ & $-0.44 * * *$ & $0.28 * *$ & 0.17 & 1 & \\
SE & $0.26 * *$ & 0.09 & 0.11 & -0.00 & $-0.67 * * *$ & 0.09 & $0.56 * * *$ & $0.34 * *$ & 1 \\
\hline$* * * \mathrm{p}<0.01 ; * * \mathrm{p}<0.05 ; * \mathrm{p}<0.10$ & & & & & & \\
\hline
\end{tabular}

Concerning the correlations, it is evident that the antecedents behave as intended towards the outcome variable, with Effort Expectancy as the only antecedent with negatively phrased items presenting the only negative correlation. Apart from Perceived Susceptibility and Facilitating Conditions, all predictors show a significant correlation. Hedonic Motivation and Performance Expectancy correlate best with Usage Intention and show the highest level of significance together with Social Influence. It is, therefore, likely that these factors are significant predictors of Usage Intention.

Several antecedents show a high and significant correlation with each other, therefore the VIF is calculated to test for multicollinearity. As Table 4 shows, no VIF in the regression analysis is greater than ten, indicating no relevant multicollinearity within the regression analysis [38]. In the PLS-SEM, no VIF exceeds 3.3, which indicates that multicollinearity and common method bias have no relevant influence there [39]. We further used Shapiro-Wilk to assess normality of the data, and several non-normal distributions were found. While this will not impact the nonparametric PLS, robust estimators were used in the regression analyses to address it. The assumptions of linearity and homoscedasticity were tested for via plotting and the Breusch-Pagan test. Both assumptions are fulfilled. 
A PLS-SEM analysis is conducted to determine the relationship between antecedents and Usage Intention. It is based on $\mathrm{N}=62$ with results shown in Figure 2. The antecedents account for a variability of $68 \%$ of the Usage Intention $\left(\mathrm{R}^{2}=0.679\right)$. This $\mathrm{R}^{2}$ makes the sample size of 62 sufficient for a statistical power of $80 \%$ and with $5 \%$ probability of error [40]. The significant positive predictors include Social Influence and Hedonic Motivation. Therefore, H5 and H8 are supported. The antecedents Perceived Susceptibility, Perceived Seriousness, Performance Expectancy, Effort Expectancy, Facilitating Conditions and Self-Efficacy showed no predictive power for Usage Intention. Therefore, hypotheses H1, H2, H3, H4, H7 and H6 are not supported when analyzing the full sample.

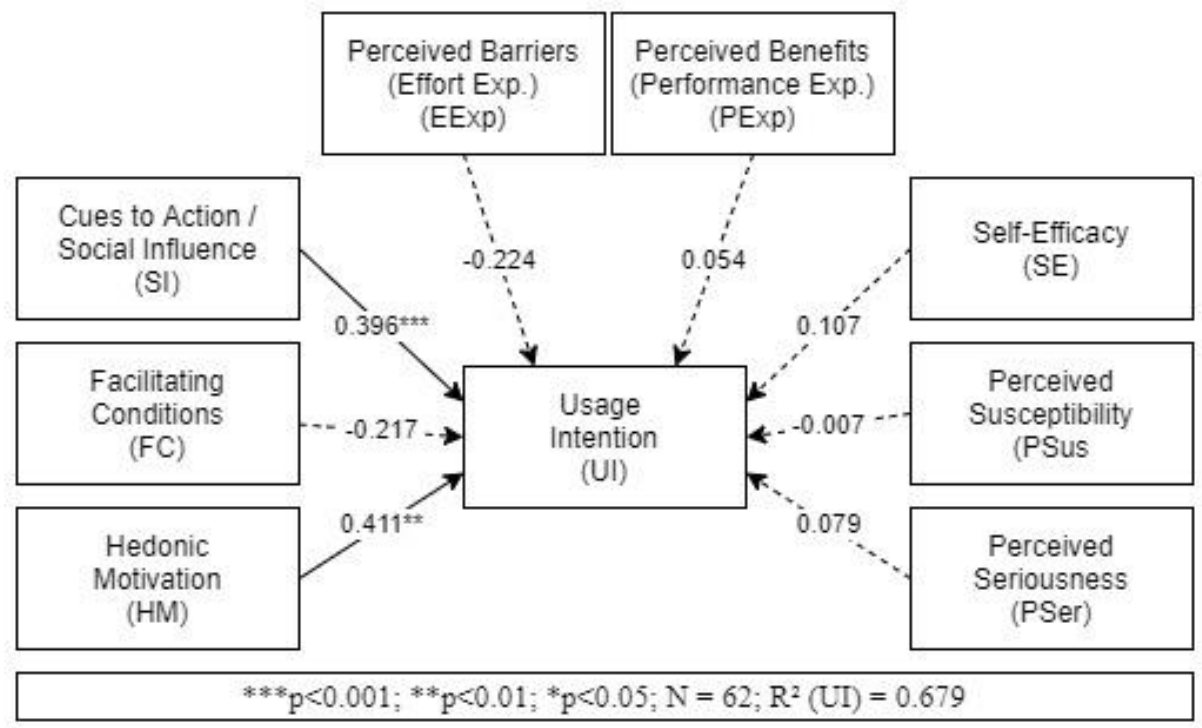

Figure 2: Path coefficients and significances in the PLS-SEM analysis

However, the full sample is not homogenous with respect to the availability of an app for documentation. On one hand, there are non-users who may want to use digital documentation, but their HTC is not supporting it. On the other hand, there are nonusers who do not use an app although their HTC supports it. The situation of the two groups of patients is objectively different so that a separate analysis is needed. A third group is formed by patients who do not know whether their HTC offers an app. We expected that hemophilia patients would be well informed about the disease and the possibilities for its management (see also Table 1) but almost 30\% of respondents crossed the "do not know" option. Accordingly, the participants could be split in a subsample that does not use digital documentation despite its availability (Group DU), another sub-sample with no access to it (Group NA) and a third group not knowing whether it is available (Group DK). Due to the smaller sample size of the subgroups (given in Table 4), we can only search for a large effect size and accept a higher probability for Type II errors. Also, since smaller sample size can decrease the 
significance level, we set the significance threshold to 0.1 in the regression analyses [41]. Table 4 presents the different multiple regression analyses.

Hedonic Motivation is the only significant antecedent for the non-informed group. It means that they do not understand what value the digital documentation may have and, therefore, would only use it as a more entertaining way to document. Participants with no current access to digital documentation expect it to be useful (Performance Expectancy) and consider themselves to be well-prepared (Self-Efficacy) for it. Lastly, participants who do not use digital documentation despite having access to it are significantly influenced by Social Influence and Perceived Seriousness. The influence by Facilitating Conditions has an unexpected negative sign which we suspect to be a Simpson paradox, which was validated by additional single variable linear regression [42]. Hence, we will exclude Facilitating Conditions from further discussion. The nonadoption by this group is surprising at first. A look at the illness severity in this group explains this behavior to some extent. because $44 \%$ of participants do not have the severe form (in other groups the share is only $21 \%$ and $12 \%$ ) and do not really need much documentation. If we add to this group app users, the share of severely ill patients rises to $78 \%$.

Table 4: Multiple Regression Analysis

\begin{tabular}{|l|l|l|l|}
\hline Variable & Group DK & Group DU & Group NA \\
\hline Perceived Susceptibility & 0.14 & -0.28 & 0.10 \\
Perceived Seriousness & -0.07 & $0.73^{*}$ & 0.05 \\
Performance Expectancy & -0.05 & -0.52 & $0.64 *$ \\
Effort Expectancy & 0.44 & -0.01 & -0.08 \\
Social Influence & 0.18 & $0.80^{* *}$ & 0.07 \\
Facilitating Conditions & 0.08 & $-0.70^{*}$ & -0.42 \\
Hedonic Motivation & $0.79 * *$ & 0.97 & 0.05 \\
Self-Efficacy & 0.49 & 0.62 & $0.88^{*}$ \\
\hline $\mathrm{R}^{2}$ & 0.77 & 0.74 & 0.59 \\
Adj. $\mathrm{R}^{2}$ & 0.58 & 0.51 & 0.39 \\
MaxVIF & 3.52 & 6.42 & 4.76 \\
$\mathrm{~N}$ & 19 & 18 & 25 \\
\hline$\%$ severe & 78 & 56 & 88 \\
\hline ***p $<0.01 ; * * \mathrm{p}<0.05 ; * \mathrm{p}<0.10$ & & \\
\hline
\end{tabular}

\section{$7 \quad$ Discussion and Conclusions}

The present study examined the factors determining the intention of patients to use $\mathrm{m}$ health for a chronic disease. Suitable factors from UTAUT2 and HBM were analyzed in a PLS-SEM and in several multiple regressions. The analysis of the full sample of non-users reveals that Social Influence and Hedonic Motivation are significant 
predictors. The significant positive relationship of Social Influence confirms the relevance of the social environment in deciding whether to use digital documentation. The more suggestions patients receive from their friends, family members, or physicians, the more inclined they are to use digital documentation. It shows a significant difference between the role of Social Influence for professionals and patients: while professionals seem to be little concerned about others' opinions [28], patients seem to rely more on advice, which makes sense given their lack of professional knowledge. These results are in line with other studies researching $\mathrm{m}$ health usage from the patients' perspective [12, 24], confirming that Social Influence should be considered when researching m-health usage intention.

Hedonic Motivation shows to be the strongest and most significant predictor, which matches the results of other adoption studies [5, 11]. It suggests that $\mathrm{m}$-health apps need to exceed their utilitarian value and provide additional features to gain the patients' interest. This may seem surprising given the serious nature of chronic diseases, but also fits the observed scenario: Patients will document their factor usage either way. Digitalization cannot be achieved by only simply digitalizing the process, but it must keep the patient engaged. M-health users value supportive functions like integrated reminders and tracking [29].

The analysis of the full sample does not disclose perceptions of patients in a specific situation. The sub-samples are small but still lead to some interesting and statistically significant findings. The group with no access to digital documentation shows a significant influence of Performance Expectancy on Usage Intention. This implies that positive expectations about $\mathrm{m}$-health are likely to lead to an increasing demand for such possibilities. Given the close and often long relationship between physicians and their patients, we do not believe that patients will switch to another physician (and HTC) for that reason but we think when patients look for a new physician (e.g., because of relocation) the opportunity to use an app for documentation will play a role. For the group of patients with access to digital documentation but who do not use it, the concern about hemophilia consequences (Perceived Seriousness) raises UI. For patients with severe hemophilia in this group, it is probably just a question of smartphone skills, cost, or time till they switch. Since they are open to Social Influence, some relating advice may help to persuade them to switch to an app. The third group which is not informed about the support of their HTC with respect to apps is puzzling. Whatever the real situation in their HTC may be, they did not care to find out. This is understandable for mild and moderate forms but not for the severe form of hemophilia (79\% in this group!). These people should know about the existence of apps for documentation from their association (or other sources).

The present study offers several theoretical contributions and practical implications. By combining UTAUT2 and HBM, the specific behavior in the health context is represented in more detail than previously [43]. It follows the appeal to explore theorybased additions to health-IT use [14]. In comparison to studies on healthcare professionals [12], our study shows that patients are different from professionals with respect to $\mathrm{m}$-health. This should be recognized when trying to persuade both groups to use m-health or when conducting studies in this domain. 
Compared to previous studies [44], our study shows the necessity of utilizing the full UTAUT2 model instead of TAM or only parts of TAM2, since significant predictors like hedonic motivation may be overlooked otherwise. Our study also shows a direct impact of social influence on adoption intention instead of just an indirect one via perceived usefulness. In other words, even if a patient does not perceive an app as useful, he may still use it if the treating physician recommends it. We can also add that the perceived usefulness, which was a central predictor to adoption attention in previous studies [44], is only a significant predictor for patients who currently have no possibility to use the respective CDM app (due to their treatment center). The study also provides some insights useful to $\mathrm{m}$-health providers and healthcare professionals on how to get patients to adopt $\mathrm{m}$-health. The significance of Social Influence demonstrates that app providers need to reach out to treating physicians and the patients' social environment, which in the case of rare chronic diseases could be done via patient associations. App providers should implement engaging and interesting additions to their apps. There are already abundant implementations of such functions in the context of general health applications. Similar features can be applied in the context of chronic diseases, where the serious nature of the disease needs to be respected, but nonetheless information should be presented in an interesting manner.

The limitations of the study are based on the measurement of intention rather than use, the small sample, and the specific context. Participants with the intention to use an app still must install and actually use the app. Therefore, a longitudinal design to track actual usage after the intention has been formed is more reliable. Unfortunately, this is especially difficult when respondents' privacy must be assured without any compromise. The number of respondents is a methodological restriction. Hence, the findings of this study can only be considered as exploratory. A higher number of participants would also allow for structural relationship modelling in subgroups, since multiple regressions cannot fully map the factors' relationships with each other.

Disease specifics do not allow a simple extension of the findings to other diseases. Hemophilia patients already have the disease. Perceived susceptibility may play a bigger role with a disease that can be contracted (e.g., various forms of cancer). The download of the app cannot be done via an app store, but it must be provided by the HTC due to the sensitivity of the data handled and the needed cooperation with the HTC/physician. If an app can be offered via an app store, the rank of the app, its public rating by other users, and similar factors may influence the adoption of such apps.

\section{References}

1. Estrin, D., Sim, I.: Open mHealth architecture: an engine for health care innovation. Science 330, 759-760 (2010)

2. Viswanathan, M., Golin, C.E., Jones, C.D., Ashok, M., Blalock, S.J., Wines, R.C.M., Coker-Schwimmer, E.J.L., Rosen, D.L., Sista, P., Lohr, K.N.: Interventions to improve adherence to self-administered medications for chronic diseases in the United States: a systematic review. Annals of internal medicine 157, 785-795 (2012) 
3. Bauer, U.E., Briss, P.A., Goodman, R.A., Bowman, B.A.: Prevention of chronic disease in the 21st century: elimination of the leading preventable causes of premature death and disability in the USA. The Lancet 384, 45-52 (2014)

4. Agnihothri, S., Cui, L., Delasay, M., Rajan, B.: The value of mHealth for managing chronic conditions. Health Care Management Science, 1-18 (2018)

5. Wang, J., Wang, Y., Wei, C., Yao, N., Yuan, A., Shan, Y., Yuan, C.: Smartphone interventions for long-term health management of chronic diseases: an integrative review. Telemedicine and e-Health 20, 570-583 (2014)

6. Brooker, M.: 2010 WFH Global Survey Report, https://www1.wfh.org/publication/files/pdf-1427.pdf

7. WHO: Diabetes, http://www.who.int/news-room/fact-sheets/detail/diabetes

8. Fischer, K., van der Bom, Johanna G, Mauser-Bunschoten, E.P., Roosendaal, G., Prejs, R., Kleijn, P. de, Grobbee, D.E., van den Berg, M.: The effects of postponing prophylactic treatment on long-term outcome in patients with severe hemophilia. Blood 99, 2337-2341 (2002)

9. Dowd, B.E., Swenson, T., Parashuram, S., Coulam, R., Kane, R.: PQRS Participation, Inappropriate Utilization of Health Care Services, and Medicare Expenditures. Medical care research and review : MCRR 73, 106-123 (2016)

10. Berntorp, E., Shapiro, A.D.: Modern haemophilia care. The Lancet 379, 14471456 (2012)

11. Venkatesh, V., Thong, J.Y.L., Xu, X.: Consumer acceptance and use of information technology: extending the unified theory of acceptance and use of technology. MIS quarterly, 157-178 (2012)

12. Sun, Y., Wang, N., Guo, X., Peng, Z.: Understanding the acceptance of mobile health services: a comparison and integration of alternative models. Journal of Electronic Commerce Research 14, 183 (2013)

13. Janz, N.K., Becker, M.H.: The health belief model: A decade later. Health education quarterly 11, 1-47 (1984)

14. Holden, R.J., Karsh, B.-T.: The technology acceptance model: its past and its future in health care. Journal of biomedical informatics 43, 159-172 (2010)

15. Huang, J.-C.: Remote health monitoring adoption model based on artificial neural networks. Expert Systems with Applications 37, 307-314 (2010)

16. Rogers, R.W.: A protection motivation theory of fear appeals and attitude change1. The journal of psychology 91, 93-114 (1975)

17. Abraham, C., Sheeran, P.: The health belief model. Predicting health behaviour 2, 28-80 (2005)

18. Harrison, J.A., Mullen, P.D., Green, L.W.: A meta-analysis of studies of the health belief model with adults. Health education research 7, 107-116 (1992)

19. Khorsandi, B., Khakbazan, Z., Mahmoodzadeh, H.A., Haghani, H., Farnam, F., Damghanian, M.: Self-efficacy of the First-degree Relatives of Patients with Breast Cancer in the Prevention of Cancer: Using the Health Belief Model. J Canc Educ (2019)

20. Gilfoyle, M., Garcia, J., Chaurasia, A., Oremus, M.: Perceived susceptibility to developing cancer and mammography screening behaviour: a cross-sectional analysis of Alberta's Tomorrow Project. Public Health 177, 135-142 (2019) 
21. Bandura, A.: Self-efficacy: toward a unifying theory of behavioral change. Psychological review 84, 191 (1977)

22. Venkatesh, V., Morris, M.G., Davis, G.B., Davis, F.D.: User acceptance of information technology: Toward a unified view. MIS quarterly, 425-478 (2003)

23. Orji, R., Vassileva, J., Mandryk, R.L.: Modeling the efficacy of persuasive strategies for different gamer types in serious games for health. User Modeling and User-Adapted Interaction 24, 453-498 (2014)

24. Diño, M.J.S., Guzman, A.B. de: Using partial least squares (PLS) in predicting behavioral intention for telehealth use among Filipino elderly. Educational Gerontology 41, 53-68 (2015)

25. Radhakrishnan, K., Xie, B., Berkley, A., Kim, M.: Barriers and facilitators for sustainability of tele-homecare programs: a systematic review. Health services research 51, 48-75 (2016)

26. Zhang, Y., Liu, C., Luo, S., Xie, Y., Liu, F., Li, X., Zhou, Z.: Factors Influencing Patients' Intentions to Use Diabetes Management Apps Based on an Extended Unified Theory of Acceptance and Use of Technology Model: Web-Based Survey. Journal of medical Internet research 21, e15023 (2019)

27. Ajzen, I.: The theory of planned behavior. Organizational behavior and human decision processes 50, 179-211 (1991)

28. Chau, P.Y.K., Hu, P.J.-H.: Information technology acceptance by individual professionals: A model comparison approach. Decision sciences 32, 699-719 (2001)

29. Funk, C.: Mobile Softwareanwendungen (Apps) im Gesundheitsbereich: Entwicklung, Marktbetrachtung und Endverbrauchermeinung. ibidem-Verlag (2013)

30. DHG: Über die Deutsche Hämophiliegesellschaft zur Bekämpfung von Blutungskrankheiten e.V., https://www.dhg.de/organisation/ueber-uns.html

31. IGH: Informationen und Ziele, https://www.igh.info/inhalte/ueberuns/informationen-und-ziele/

32. Maiman, L.A., Becker, M.H.: The health belief model: Origins and correlates in psychological theory. Health Education Monographs 2, 336-353 (1974)

33. Champion, V.L.: Instrument development for health belief model constructs. Advances in Nursing Science (1984)

34. Cho, J., Quinlan, M.M., Park, D., Noh, G.-Y.: Determinants of adoption of smartphone health apps among college students. American journal of health behavior 38, 860-870 (2014)

35. Bhattacherjee, A., Perols, J., Sanford, C.: Information technology continuance: A theoretic extension and empirical test. Journal of Computer Information Systems 49, 17-26 (2007)

36. Thomas, M.A., Li, Y., Oliveira, T.: Nuances of development contexts for ICT4D research in least developed countries: An empirical investigation in Haiti. Telematics and Informatics 34, 1093-1112 (2017)

37. Hair, J.F., Black, W.C., Babin, B.J., Anderson, R.E. and Tatham, R.L.: Multivariate data analysis (Vol. 6). Upper Saddle River, NJ: Pearson Prentice Hall (2006) 
38. Menard, S.: Applied logistic regression analysis. Sage (1995)

39. Ned Kock: Common Method Bias in PLS-SEM: A Full Collinearity Assessment Approach. IJeC 11, 1-10

40. Joseph F. Hair, JR., Hult, G.T.M., Ringle, C., Sarstedt, M.: A Primer on Partial Least Squares Structural Equation Modeling (PLS-SEM). SAGE Publications (2016)

41. Cohen, J., Cohen, P., West, S.G., Aiken, L.S.: Applied Multiple

Regression/Correlation Analysis for the Behavioral Sciences. Routledge (2013)

42. Hernán, M.A., Clayton, D., Keiding, N.: The Simpson's paradox unraveled. International journal of epidemiology 40, 780-785 (2011)

43. Akter, S., D’Ambra, J., Ray, P.: Development and validation of an instrument to measure user perceived service quality of mHealth. Information \& Management 50, 181-195 (2013)

44. Dou, K., Yu, P., Deng, N., Liu, F., Guan, Y., Li, Z., Ji, Y., Du, N., Lu, X., Duan, H.: Patients' Acceptance of Smartphone Health Technology for Chronic Disease Management: A Theoretical Model and Empirical Test. JMIR mHealth and uHealth (2017) 